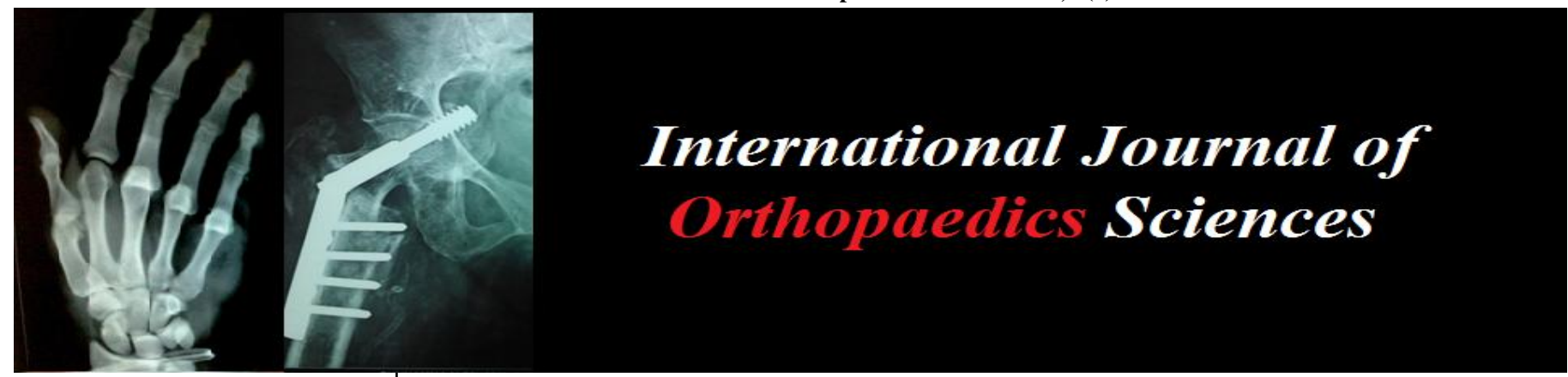

ISSN: $2395-1958$

IJOS 2018; 4(2): 164-168

(C) 2018 IJOS

www.orthopaper.com

Received: 17-02-2018

Accepted: 20-03-2018

Dr. Yogendra Kumar

Department of Orthopaedics\& Rehabilitation J.L.N. Medical College \& Associated Group of Hospitals, Ajmer, Rajasthan, India

Dr. Hemeshwer Harshwardhan Department of Orthopaedics\& Rehabilitation J.L.N. Medical College \& Associated Group of Hospitals, Ajmer, Rajasthan, India
Correspondence

Dr. Yogendra Kumar

Department of Orthopaedics\& Rehabilitation J. L. N. Medical College \& Associated Group of Hospitals, Ajmer, Rajasthan, India

\section{Comparison of proximal femur locking compression plate and proximal femur nail in treatment of complex proximal femoral fractures}

\section{Dr. Yogendra Kumar and Dr. Hemeshwer Harshwardhan}

DOI: https://doi.org/10.22271/ortho.2018.v4.i2c.26

\section{Abstract}

Background: Proximal femur fractures are common injuries that mostly affect the elderly population. In young and healthy individuals, the injury results from high energy trauma, whereas these fractures are common in the elderly persons due to low energy trauma like simple fall.

Methods: 20 patients treated by proximal femoral locking compression plate and 20 patients treated by proximal femoral nailing which operated for complex proximal femoral fractures(AO31 A2.3 and A3.3) selected for this prospective study.

Results: Average operating time in PF-LCP is 66.05 mins (range 55.72-76.58mins) and in PFN was 49 mins (range 39.46-58.54 mins). Average blood loss in PF-LCP was $361.50 \mathrm{ml}$ (range 303.98-419.02ml) and in PFN was $260.00 \mathrm{ml}$ (range 204.37-315.63 ml). 8(40.0\%) patients treated by PF-LCP had postoperative complications in which 1 had early deep infection, 2 had proximal screw back out, 3 had varus collapse and 2 had shorting $>1 \mathrm{~cm} .4(20.0 \%)$ patients treated by PFN had postoperative complications in which 1 had screw back out 1 had varus collapse and 2 had shortening $>1 \mathrm{~cm}$. Radiological union was seen in all 40(100\%) cases and Average Harris hip score in patients treated with PFN is 90.0 (range 83.79-96.21)) and in PF-LCP is 81.15(71.56-90.74).

Conclusions: The Functional outcome was better for PFN then PF-LCP.

Keywords: Complex proximal femoral fractures, proximal femur locking compression plate and proximal femur nail

\section{Introduction}

Proximal femur fractures are common injuries that mostly affect the elderly population. In young and healthy individuals, the injury results from high energy trauma, whereas these fractures are common in the elderly persons due to osteoporosis and $90 \%$ of fractures result from a simple fall ${ }^{[1]}$.

The present choice of treatment for proximal femur fractures is reduction and stable internal fixation so that mobilization can be done as early as possible to prevent the morbidity and mortality. Many internal devices have been used in treatment of proximal femur fractures because of high incidence of complications reported after surgical treatment with each implant. Lack of satisfactory implant in surgical treatment of peritrochanteric fractures has led to series of evolution in design of a perfect implant. Hence proximal femoral fractures are challenging. Various treatment modalities are available for many of these fractures-Plate constructs (Fixed angle device, sliding hip screw, linear compression class and hybrid locking class), Cephallomedullary interlocking nails (impaction class, dynamic compression, reconstruction and inter TAN nail). Dynamic hip screw (DHS) is the gold standard treatment for stable intertrochanteric fractures ${ }^{[2]}$.

In case of unstable intertrochanteric fractures, the incidence of limb shortening, medialization of distal fragment and implant cut outs are high. In this case, proximal femur nail (PFN) is the implant of choice ${ }^{[3]}$. PFN has additional anti rotation pin or set pin used to prevent the rotational strain at the fracture site. Due to the better understanding of bio-mechanics of hip fracture geometry this technique could provide better results ${ }^{[4]}$.

In certain cases, like greater trochanter or lateral wall fracture type in proximal femoral fractures, PFN cannot be performed ${ }^{[5]}$. 
In those cases, dynamic condylar screw (DCS) is the treatment of choice, but, if there is more comminution in lateral wall, DCS is difficult to perform ${ }^{[6]}$. The lateral trochanteric wall is believed to be an important factor in stabilizing pertrochanteric fractures, keeping the lateral wall intact reduces the rates of malunion and nonunion as well as can assist in fracture healing. This led to the development of newer methods like proximal femur Locking Compression Plate (PF-LCP). It is the feasible alternative for the treatment [7]. The multiple locking screw holes of the PF-LCP provide various options to tackle complex fracture pattern. It functions as an internalized external fixator and minimizes the pressure on the periosteum and encourages biological healing ${ }^{[8]}$.

\section{Methods and Materials}

This study was conducted in Department of Orthopaedics, J. L. N. Medical College \& Associated Group of Hospitals, Ajmer. 40 cases for the study were selected which operated for complex proximal femoral fractures by proximal femur locking compression plate and proximal femur nail from January 2016 to June 2017.

\section{Method of collection of data}

1. A case documentation form was used to obtain data, including age, sex, mechanism of injury, type of fracture according to AO/OTA classification.

2. Radiological investigations-Hip with thigh (AP view) and knee with thigh X-ray (AP \& lateral view)

\section{Inclusion Criteria}

\section{- $\quad$ Age $\geq 18$ years}

- Patients with closed comminuted intertrochanteric with posteromedial multifragments (AO31-A2.3) and comminuted pertrochanteric reverse oblique multifragments fractures (AO 31-A3.3) with or without subtrochanteric extension.

\section{Exclusion Criteria}

- Pathologic fracture

- Any medical illness (Inability to walk independently prior to injury)

Preoperatively all the patients were evaluated carefully includes detailed history, the cause of fracture and other associated diseases. The radiograph of the pelvis with both hips AP view, Hip with thigh (AP view) and knee with thigh X-ray (AP \& lateral view) were taken. The fractures were classified using AO classification. Skin traction was applied to all the cases initially. Implants either PF-LCP or PFN were randomly selected.

Under anesthesia the patient was put to the fracture table. Closed reduction was done by longitudinal traction and evaluated under $\mathrm{C}$-arm image intensifier. The part was prepared with $10 \%$ beta dine solution and properly draped. Standard lateral approach to the proximal femur was used in all cases of PF-LCP through minimally invasive approach while all cases of PFN fixation were operated with an incision over the tip of trochanter. Blood loss amount is estimated by blood absorbed by surgical gauze using Gauze Visual Analogue and vacuum suction drain. After fixation wound was closed in layers and sterile dressing was done. Operating time was estimated from incision to closure. Post-operative I.V. antibiotic given for 5 days and then changed to oral antibiotic. Patients were encouraged to activity mobilize the knee, ankle and hip from the 2nd postoperative day. Sutures were removed after 10 days. Patients were followed up clinically, radiographically at regular intervals monthly for 3 months and then every 3 monthly. Functional outcome of the patient were assessed using HARRIS HIP SCORING system. Results were recorded in relation to duration of surgery, amount of blood loss, post-operative complications, union and functional outcome.

\section{Result}

Table 1: Age Distribution

\begin{tabular}{|c|c|c|c|c|c|}
\hline & PF-LCP (n=20) & PFN (n=20) & \multirow{2}{*}{ Total } & p-value \\
\hline & & No. of patients (\%) & No. of patients (\%) & & \multirow{7}{*}{0.1478} \\
\hline \multirow{4}{*}{ Age Group (Years) } & $21-40$ & $8(40.00 \%)$ & $6(30.00 \%)$ & $14(35.00 \%)$ & \\
\hline & $41-60$ & $8(40.00 \%)$ & $7(35.00 \%)$ & $15(37.50 \%)$ & \\
\hline & $61-80$ & $4(20.00 \%)$ & $4(20.00 \%)$ & $8(20.00 \%)$ & \\
\hline & $>80$ & $0(0.00 \%)$ & $3(15.00 \%)$ & $3(7.50 \%)$ & \\
\hline \multicolumn{2}{|l|}{ Total } & $20(100.00 \%)$ & $20(100.00 \%)$ & $40(100.00 \%)$ & \\
\hline \multicolumn{2}{|l|}{ Mean \pm S. D. } & $46.10 \pm 12.97$ & $54.60 \pm 22.22$ & & \\
\hline
\end{tabular}

In our study of 40 cases of complex proximal femoral fractures were evaluated. Out of 33 males, 17 (51.52\%) had right side fractures and $16(48.48 \%)$ had left sides fractures. Out of 7 females, $5(71.43 \%)$ had right sided fractures and 2
(28.57\%) had left sided fractures. Average age of patients treated by PF- LCP was $46.1 \pm 12.97$ years while in PFN was $54.60 \pm 22.22$ years. $\mathrm{P}$-value is equal to 0.1478 which is statistically not significant (Table 1).

Table 2: Average operative time

\begin{tabular}{|c|c|c|c|c|c|}
\hline \multirow{2}{*}{ AOT } & \multicolumn{2}{|c|}{ PF-LCP $(n=20)$} & \multicolumn{2}{|c|}{ PFN $(n=20)$} & \multirow{2}{*}{ p-value } \\
\hline & Frequency & Percentage & Frequency & Percentage & \\
\hline $31-40 \mathrm{~min}$ & 0 & $0.00 \%$ & 5 & $25.00 \%$ & \multirow{8}{*}{0.0001} \\
\hline $41-50 \mathrm{~min}$ & 2 & $10.00 \%$ & 10 & $50.00 \%$ & \\
\hline $51-60 \mathrm{~min}$ & 5 & $25.00 \%$ & 2 & $10.00 \%$ & \\
\hline $61-70 \min$ & 8 & $40.00 \%$ & 3 & $15.00 \%$ & \\
\hline $71-80$ min & 3 & $15.00 \%$ & 0 & $0.00 \%$ & \\
\hline $81-90 \mathrm{~min}$ & 2 & $10.00 \%$ & 0 & $0.00 \%$ & \\
\hline Total & 20 & $100.00 \%$ & 20 & $100.00 \%$ & \\
\hline Mean \pm S.D. & \multicolumn{2}{|c|}{$66.05 \pm 10.33$} & \multicolumn{2}{|c|}{$49.00 \pm 9.54$} & \\
\hline
\end{tabular}


Average operating time in PF-LCP was 66.05 (range 55.7276.58 mins) and in PFN was 49.0 (range 39.46-58.54 mins).
$\mathrm{P}$-value is equal to 0.0001 which is statistically significant (Table 2).

Table 3: Average Blood Loss

\begin{tabular}{|c|c|c|c|c|c|}
\hline \multirow{2}{*}{ Blood Loss } & \multicolumn{2}{|c|}{ PF-LCP $(n=20)$} & \multicolumn{2}{|c|}{ PFN $(n=20)$} & \multirow{2}{*}{ p- value } \\
\hline & Frequency & Percentage & Frequency & Percentage & \\
\hline $101-150 \mathrm{ml}$ & 0 & $0.00 \%$ & 1 & $5.00 \%$ & \multirow{9}{*}{$<0.0001$} \\
\hline $151-200 \mathrm{ml}$ & 0 & $0.00 \%$ & 3 & $15.00 \%$ & \\
\hline $201-250 \mathrm{ml}$ & 1 & $5.00 \%$ & 6 & $30.00 \%$ & \\
\hline $251-300 \mathrm{ml}$ & 3 & $15.00 \%$ & 5 & $25.00 \%$ & \\
\hline $301-350 \mathrm{ml}$ & 5 & $25.00 \%$ & 5 & $25.00 \%$ & \\
\hline $351-400 \mathrm{ml}$ & 5 & $25.00 \%$ & 0 & $0.00 \%$ & \\
\hline $401-450 \mathrm{ml}$ & 6 & $30.00 \%$ & 0 & $0.00 \%$ & \\
\hline Total & 20 & $100.00 \%$ & 20 & $100.00 \%$ & \\
\hline Mean +S. D. & \multicolumn{2}{|c|}{$361.50 \pm 57.52$} & \multicolumn{2}{|c|}{$260.00 \pm 55.63$} & \\
\hline
\end{tabular}

Average blood loss in PF-LCP was 361.50 (Large 303.98419.02ml) and in PFN was 260.0 (range 204.37-315.63 ml) p- value is less than 0.0001 which is statistically significant (Table 3).

Table 4: Radiological Union

\begin{tabular}{|c|c|c|c|c|c|}
\hline \multirow{2}{*}{ Union (Weeks) } & \multicolumn{2}{|c|}{ PF-LCP (n=20) } & \multicolumn{2}{c|}{ PFN (n=20) } & \multirow{2}{*}{ p-value } \\
\cline { 2 - 5 } & No. of patients & Percentage & No. of patients & Percentage & \\
\hline$\leq 12$ & 0 & $0.00 \%$ & 2 & $10.00 \%$ & \\
\hline $13-16$ & 10 & $50.00 \%$ & 15 & $75.00 \%$ & \multirow{2}{*}{0.0133} \\
\hline $17-20$ & 9 & $45.00 \%$ & 3 & $0.00 \%$ & \\
\hline $21-24$ & 1 & $5.00 \%$ & 0 & $100.00 \%$ & \\
\hline Total & 20 & $100.00 \%$ & 20 & $16.10 \pm 2.10$ & \\
\hline Mean \pm S.D. & \multicolumn{2}{|c|}{$17.80 \pm 2.04$} & \multicolumn{2}{c}{} \\
\hline
\end{tabular}

Radiological union was seen in all 40(100\%) cases. Out of 20 patients treated by PF-LCP, average union time was 17.80 weeks (range 15.76-19.84 weeks). Out of 20 patients treated by PFN, Average union time was 16.10 weeks (range 14.018.2 weeks) (Table 4).

Table 5: Postoperative Complications

\begin{tabular}{|c|c|c|c|c|c|}
\hline \multirow{2}{*}{ Complications } & \multicolumn{2}{|c|}{ PF-LCP (n=20) } & \multicolumn{2}{c|}{ PFN (n=20) } & \multirow{2}{*}{ Total } \\
\cline { 2 - 5 } & No. of patients & Percentage & No. of patients & Percentage & \\
\hline Infection & 1 & $5.00 \%$ & 0 & $0.00 \%$ & $1(2.50 \%)$ \\
\hline Implant failure (Screw back out) & 2 & $10.00 \%$ & 1 & $5.00 \%$ & $3(7.50 \%)$ \\
\hline Varus collapse & 3 & $15.00 \%$ & 1 & $5.00 \%$ & $4(10.00 \%)$ \\
\hline Shortening >1cm & 2 & $10.00 \%$ & 2 & $10.00 \%$ & $4(10.00 \%)$ \\
\hline Total & 8 & $40.00 \%$ & 4 & $20.00 \%$ & $12(30.00 \%)$ \\
\hline
\end{tabular}

In our study out of 40 cases, 12(30.00\%) cases having postoperative complication. Out of 20 patients treated by PFLCP, total $8(40.00 \%)$ patients had postoperative complication in which $1(5.0 \%)$ had early deep infection, 2(10.0\%) associated with implant failure (proximal screw back out) $3(15.0 \%)$ had varus collapse and $2(10.0 \%)$ patients had shorting $>1 \mathrm{~cm}$. Out of 20 patients treated by PFN, 4(20\%) had postoperative complication in which, $1(5.0 \%)$ had screw back out, $1(50 \%)$ had varus collapse and $2(10.0 \%)$ had shortening $>1 \mathrm{~cm}$. (Table5).
Table 6: Harris Hip Score

\begin{tabular}{|c|c|c|c|}
\hline & PF-LCP $(\mathbf{n}=20)$ & PFN $(\mathbf{n}=20)$ & P- value \\
\cline { 2 - 3 } & Mean \pm S. D. & Mean \pm S. D. & \multirow{2}{*}{0.0013} \\
\hline HHS & $81.15 \pm 9.59$ & $90.00 \pm 6.21$ & \\
\hline
\end{tabular}

Average Harris Hip Score in patient treated with PF-LCP is 81.15 (range 71.56 - 90.74) and in PFN is 90.0 (range 83.7996.21) p-value is equal to 0.0013 which is statistically significant (Table 6).

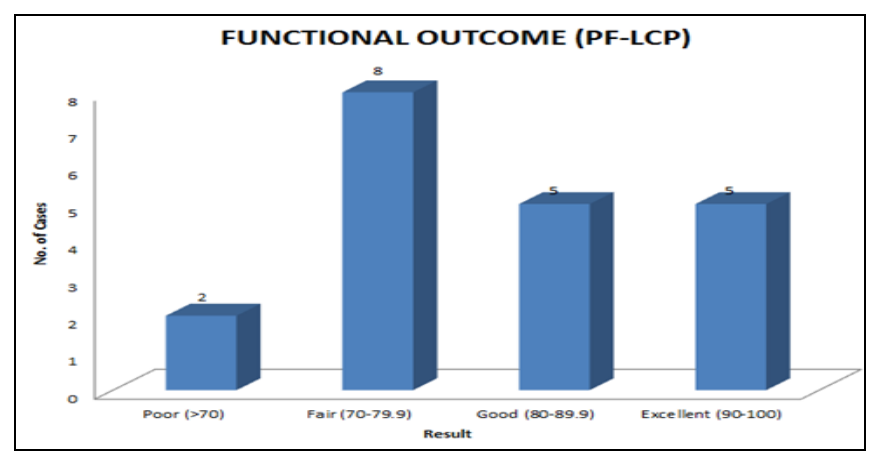

Graph 1 


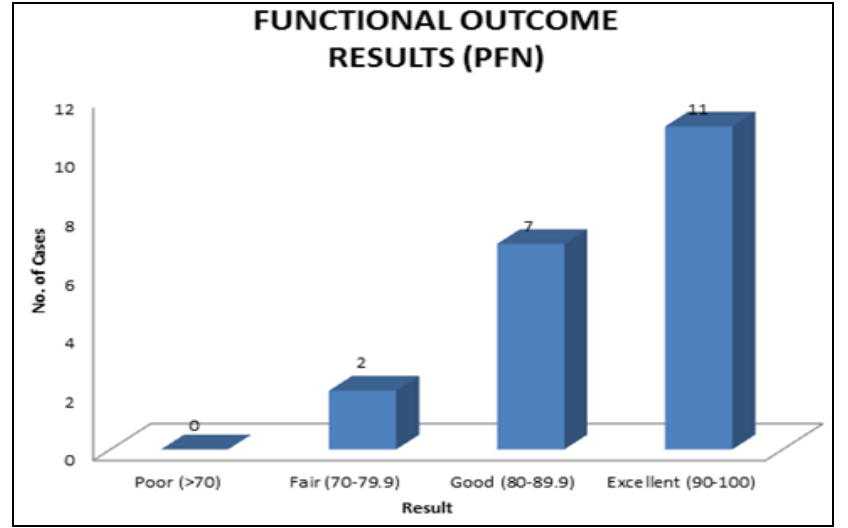

Comparing the outcome of PF-LCP and PFN with HARRIS HIP SCORE, PF-LCP had $10.0 \%$ poor, $40.0 \%$ fair, $25.0 \%$ good, $25.0 \%$ excellent results. PFN had $0 \%$ Poor, $10.0 \%$ fair, $35.0 \%$ Good and $55.0 \%$ excellent results. P-value is equal to 0.0013 which is statistically significant (Graph. 1).

\section{Discussion}

In this study of 40 cases of complex proximal femoral fractures were evaluated. Trivial trauma of domestic simple fall on ground was the commonest cause of fracture attributed to $52.50 \%$. Studies suggest that these fractures are more common in females due to postmenopausal osteoporosis as reported by David ${ }^{[9]}$, but in our study greater number of male patients $33(82.50 \%)$ were affected and female patients were
7(17.50\%) probably due to outdoor activities in our rural set up. The most common mode of trauma is simple fall on ground in the older age group and road traffic accidents in younger patients. In our study, we found that the surgery time was considerably lower in the PFN group primarily because it is a closed procedure, and less dissection was required as compared to PF-LCP fixation. Saini P, Kumar R, Shekhawat $\mathrm{V}{ }^{[10]}$ based on their study in 2013 mean operating time for PF-LCP was $79.5 \mathrm{~min}$ and total blood loss averaged 233.13 $\mathrm{ml}$. Union was achieved in all cases. Probably due to more soft tissue dissection and long exposure time, 1(5.0\%) case presented with wound infection in PF-LCP group, compared to none in the PFN group. However, the closed nature of the procedure in PFN caused a significantly increased fluoroscopic exposure during surgery. Vinay N and Sain A ${ }^{[11]}$ reported similar results in their comparative study, that is Average operating time in PFN was 67(range 73.42-61.58 mins) and in PF-LCP is 81.5(range 90.71-72.29 mins).. The amount of exposure, however, significantly reduced as the surgeon gained experience in the procedure. $2(10.0 \%)$ patient associated with implant failure (proximal screw backout) in PF-LCP group (Case 1). This was associated with varus angulation at the fracture site. Streubel PN, Moustoukas MJ, Obremskey WTA ${ }^{[12]}$ in 2013 noted high rate of mechanical failure with proximal locking plate fixation of unstable proximal femur fractures.

Case 1: Clinical \& Radiological Photographs

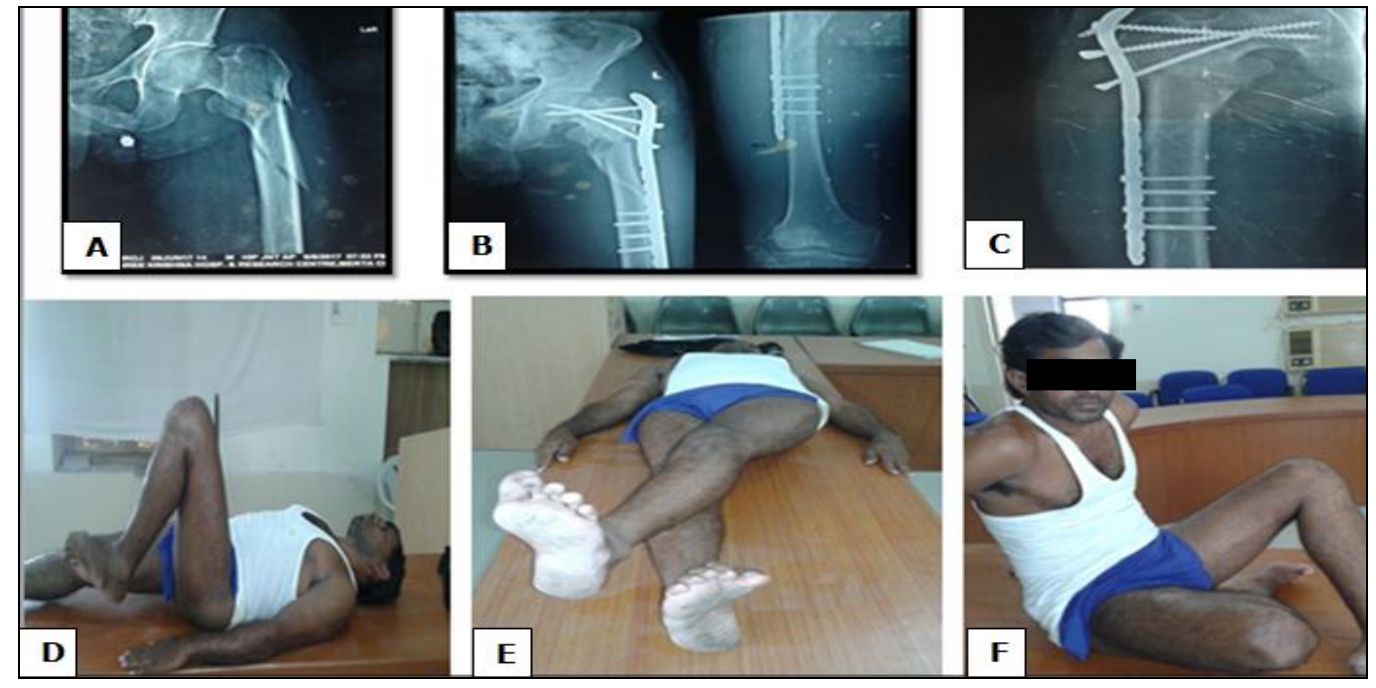

Fig 1: Radiographs of case 1. A= Pre-op X-ray of proximal femur fracture left B= Post-op X-ray with PF-LCP, C= Post-op X-ray with PF-LCP 3 month old with screw backout and varus fixation. D, E, F Clinical photograph of case 1, in flexion, in adduction and squatting position.

No significant difference was found between union time of the two groups, but the PFN group united slightly earlier (mean 16.10 weeks) than the PF-LCP group (mean 17.80 weeks) (Case 2). This might be because patients in the PFN group were able to commence mobilization earlier which improved microcirculation at the fracture site. In the postoperative period, depending on the pain and tolerance of the patient, they were made to stand with support on the 4th or 5th postoperative day. They were gradually mobilized over the next 2-3 days until they could do the non-weight bearing ambulation with a walker.

CASE 2: Clinical \& Radiological Photographs
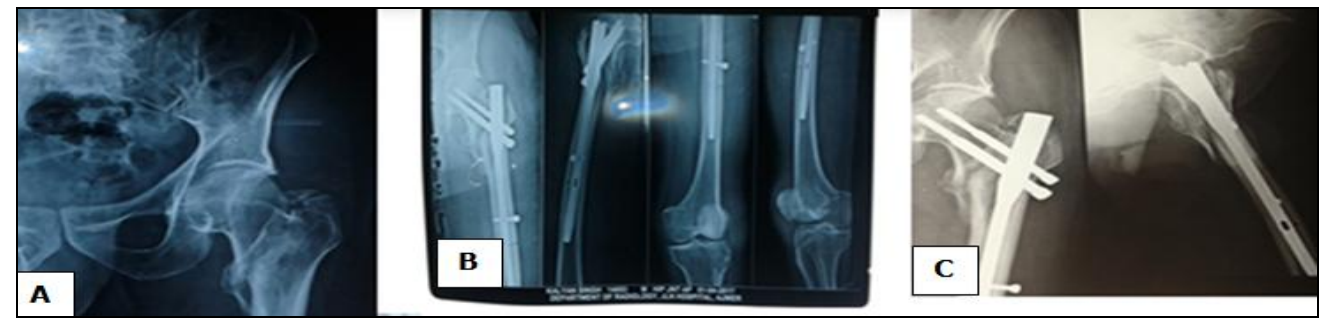


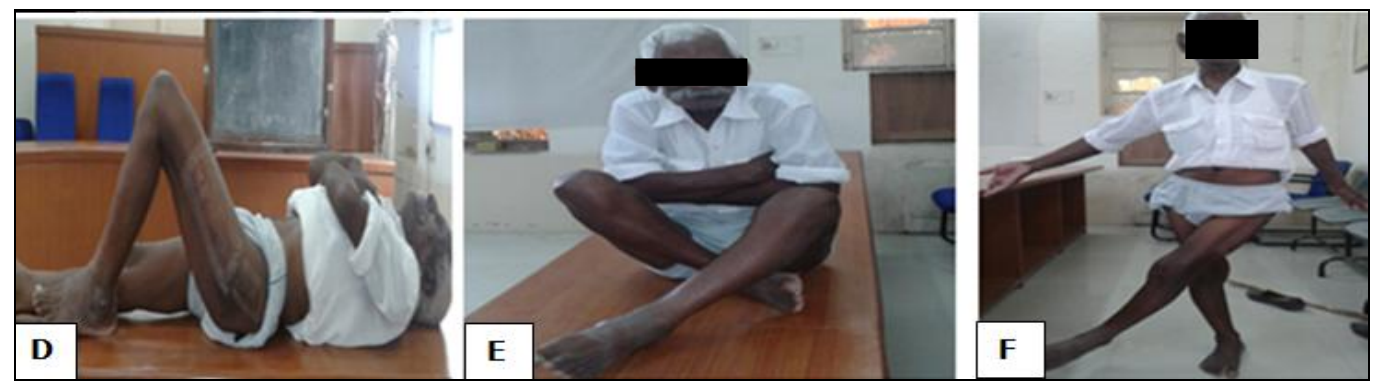

Fig 2: Radiographs of case 2. A= Unstable proximal femur fracture left, B= Immediate post-operative radiograph with PFN, C Post-op X-ray with PFN 3 month old with progressive union. D, E, F Clinical photograph of case 2, in flexion, in squatting position and adduction

The patients treated with PFN had earlier full weight bearing without support at an early post op period than the PF-LCP group patients. The result concurred with studies. In 2013 Mirbolook, Babak Siavashi, Adel et al. ${ }^{[13]}$ concluded that the results of pertrochanteric fracture fixation by intramedullary or locking plate were similar and had the same outcome. Neither treatment has statistically significant difference in complications, onset of complications incidence, and time of full-weight bearing. Earlier weight bearing was possible in the PFN group mainly due to it being an intramedullary device which acts as a load sharing rather than a load-bearing device and counteracts the varus force of hip adductors by abutting to the lateral cortex of femur. Moreover, there were less soft tissue dissection during surgery which led to earlier healing. As the surgical wound in fractures treated by PFN is small, the mean blood loss was relatively small compared to those treated by PF-LCP. The average blood loss in patients operated with PFN was $260.0 \mathrm{ml}$ rather than $361.50 \mathrm{ml}$ in PFLCP. Taeger et al. ${ }^{[14]}$ showed a $43 \%$ increased blood loss in a reduction of complex unstable fractures compared to stable ones.

The functional harris hip score was significantly better in the PFN group (mean 90.0) than with the PF-LCP group (mean 81.15). The better PFN scores could be attributed to lesser postoperative pain in the patients due to lesser soft tissue dissection and early resumption of mobilization. The poor result in PF-LCP group could also be attributed to other associated factors like development of postoperative infection and unstable fixation with screw back out.

\section{Conclusion}

For the management of complex proximal femoral fractures, PFN produces better results than PF-LCP in terms of shorter operative time, less blood loss, earlier weight bearing, lower infection rates, and better functional outcomes.

\section{Declarations}

Ethical approval: The study was approved by the institutional ethics committee

\section{References}

1. Nieves JW, Bilezikian JP, Lane JM, Einhorn TA, Wang Y, Steinbuch M et al. Fragility fractures of the hip and femur: incidence and patient characteristics. Osteoporos Int. 2010; 21(3):399-408.

2. Wolfgang GL, Bryant MH, Oneill JP. Treatment of intertrochanteric fracture of the femur using sliding screw plate fixation. Clin Orthop Relat Res. 1982; 163:148-58.

3. Kokoroghiannis C, Aktselis I, Deligeorgis A, Fragkomichalos E, Papadimas D, Pappadas I. Evolving concepts of stability and inter-medullary fixation of intertrochanteric fractures-a review. Injury. 2012; 43(6):686-93.

4. Haidukewych GJ. Intertrochanteric fracture: ten tips to improve results. J Bone Joint Surg Arm. 2009; 91:712-9.

5. Palm H, Jacobsen S, Sonne HS, Gebuhr P. Hip fracture study group integrity of the lateral femoral wall in intertrochanteric hip fractures: an important predictor of a reoperation. J Bone Joint Surg Am. 2007; 89(3):470-5.

6. Kinast C, Bolhofner BR, Mast JW, Ganz R. Pertrochanteric fractures of the femur results of treatment with the 95 degrees condylar blade-plate. Clin Orthop Relat Res. 1989; 238:122-30.

7. Ozkan K, Türkmen I, Sahin A, Yildiz Y, Erturk S, Soylemez MS. A biomechanical comparison of proximal femoral nails and locking proximal anatomic femoral plates in femoral fracture fixation a study on synthetic bones. Indian J Orthop. 2015; 49: 347-51.

8. Egol KA, Kubiak EN, Fulkerson E, Kummer FJ, Koval KJ. Biomechanics of locked plates and screws. J Orthop Trauma. 2004; 18(8):488-493.

9. David GL. Fractures and dislocation of hip. Campbell's operative orthopaedics. 11th ed. Chapter 52. Volume 3. Philadelphia, Pennsylvania, USA: Mosby Elsevier, 2010, 3237-3308.

10. Saini P, Kumar R, Shekhawat V. Biological fixation of comminuted pertrochanteric fractures with proximal femur locking compression plate; Injury. 2013; 44(2):226-31.

11. Vinay N, Sain Arnab. Comparative evaluation of clinicoradiological and functional outcome of proximal femoral locking compression plate and proximal femoral nail in unstable proximal femoral fractures, IJOS. 2016; 2(3):103-107.

12. Streubel PN, Moustoukas MJ, Obremskey WT. Mechanical failure after locking plate fixation of unstable intertrochanteric femur fractures; J Orthop Trauma. 2013; 27(1):22-8.

13. Mirbolook, Babak Siavashi, Adel Ebrahimpour Jafarinezhad, Sina Khajeh Jahromi, Maral Farahmand, Melina Roohi Rad et al. Pertrochanteric Fractures: Comparison of Proximal Femur Locking Plate and Intramedullary Locking Nail Fixation Outcome Ahmadreza; Indian Journal of Surgery, 2013.

14. Taeger G, Schmid C, Zettl R, Schweiberer L, Nastkolb D. Stable and unstable pertrochanteric femoral fractures. Differentiated indications for the dynamic hip screw. Unfallchirurg. 2000; 103:741-8. 